\title{
PAPER
}

\section{Failure to detect Chlamydia pneumoniae DNA in cerebral aneursymal sac tissue with two different polymerase chain reaction methods}

\author{
S Cagli, N Okłar, T Dalbasti, S Erensoy, N Özdamar, S Göksel, A Sayiner, A Bilgiç
}

J Neurol Neurosurg Psychiatry 2003;74:756-759

See end of article for authors' affiliations

Correspondence to: Professor N Oktar, Ege Üniversitesi Tip Fak Hast, Nörosirürii AbD, Bornova Izmir TR35100, Turkey: noktar@med.ege.edu.tr

Received

22 November 2002

Accepted in revised form

17 January 2003
Objective: Chlamydia pneumoniae ( $C$ pneumoniae) is a common cause of a usually mild, community acquired pneumonia. This organism, however, can spread from the respiratory tract into other parts of the body and has been detected in up to $70 \%$ of atheromatous lesions in blood vessels. Although the exact mechanism of the $C$ Pneumoniae contribution to the pathogenesis of atherosclerosis remains unknown, prophylactic antibiotic trials are planned for people at high risk for coronary disease.

Method: In this study the authors aimed to investigate $C$ pneumoniae DNA content in the cerebral aneurysmal sac tissue with the aid of polymerase chain reaction (PCR) method. $C$ pneumoniae DNA was searched in 15 surgically clipped and removed aneurysmal sac tissue and in two tumour (an ependymoma of the fourth ventricle and a craniofaringoma) samples by touchdown enzyme time release PCR (TETR PCR) targeting 16S rRNA gene and by nested PCR targeting ompA gene.

Results: Both PCR methods were sensitive to detect in $C$ pneumoniae $4 \times 10^{-2}$ genomes. $C$ pneumoniae DNA was not detected in any of the 17 sample tissues of these patients.

Conclusion: The contribution of $C$ pneumoniae in the development of intracranial aneurysms cannot be excluded despite the results of this study. Further studies on the possible role of $C$ pneumoniae or any other micro-organisms in the pathogenesis of aneurysms should be performed.

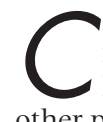
hlamydia pneumoniae is a common cause of a usually mild, community acquired pneumonia. This organism, however, can spread from the respiratory tract into other parts of the body and has been detected in up to $70 \%$ of atheromatous lesions in blood vessels. ${ }^{1}$ Although the exact mechanism of the contribution of $C$ pneumoniae to the pathogenesis of atherosclerosis remains unknown, prophylactic antibiotic trials are planned for people at high risk for coronary disease ${ }^{2}$ and even for the abdominal aortic aneurysm. ${ }^{3}$ For years chlamydia were thought to lack key enzymes and cellular machinery for generating ATP, instead sequestering host nucleoside triphosphates by translocation mechanism. The new sequence does reveal two potential ATP/ADP translocases, but it also identifies genes that may allow chlamydia to generate at least minimal amounts of ATP on its own. A unique family of 18 surface exposed outer membrane proteins (POMPs) were recently identified in the unfinished $C$ genome. $^{4}$

In recent studies investigating the presence of $C$ pneumoniae DNA in the wall of abdominal aortic aneurysms (AAA) authors $^{5-8}$ concluded that $C$ pneumoniae was often present in AAA in a viable form and that $C$ pneumoniae was linked to the pathogenesis of AAA. On the other hand some studies failed to detect $C$ pneumoniae in symptomatic $\mathrm{AAA}^{9}$ or any clinical correlation between atherosclerotic plaque behaviour in patients with established carotid artery stenosis (tables 1 and 2). ${ }^{10}$

In this study we aimed to determine and analyse $C$ pneumoniae DNA content in the cerebral aneurysmal sac tissue with the aid of polymerase chain reaction (PCR) method.

\section{METHODS}

The study group consisted of 15 patients operated transcranially for cerebral aneurysm (six women, nine men, mean age 48.7 years) (table 3 ). Specimens from the aneurysm wall were taken peroperatively, after prompt clipping under sterile conditions. Two tumour specimens (an ependymoma of the fourth ventricle and a craniopharingioma) were also collected for $C$ pneumoniae DNA analyses (table 4). The specimens from these groups were frozen at $-70^{\circ} \mathrm{C}$ immediately after collection.

\section{DNA extraction}

C pneumoniae DNA from tissue samples was extracted with High Pure PCR Template Preperation Kit (Roche Diagnostics, Indianapolis, USA).

\section{PCR}

Touchdown enzyme time release (TETR) PCR targeting the 16S rRNA gene and a nested PCR targeting the ompA gene were performed to detect $C$ pneumoniae DNA. All amplification reactions were done in a volume of $50 \mu \mathrm{l}$ containing $200 \mu \mathrm{M}$ of four deoxynucleoside triphosphates, 1.5U of AmpliTaq Gold DNA polymerase (Amplitaq Gold; Perkin-Elmer, Branchburg, NJ, USA). Different concentrations of primers and $\mathrm{MgCl} 2$ were used for each PCR. Amplification reactions were performed on a GeneAmp9600 thermocycler (Perkin-Elmer, Branchburg, NJ, USA) using different cycling conditions for each PCR. Published PCR protocols were used for both TETR $\mathrm{PCR}^{17}$ and nested $\mathrm{PCR}^{18}$ with some modifications. PCR primers tested were CPN90 5' GGT CTC AAC CCC ATC CGT GTC GG 3', CPN91 5' TGC GGA AAG CTG TAT TTC TAC AGT T 3', CPI 5' TTA CAA GCC TTG CCT GTA GG 3', CP2 5' GCG ATC CCA AAT GTT TAA GGC 3', CPC 5' TTA TTA ATT GAT GGT ACA ATA 3' and CPD 5' ATC TAC GGC AGT AGT ATA GTT 3'.

Briefly TETR PCR was performed using CPN90-CPN91 primer pair with a $0.25 \mu \mathrm{M}$ concentration of each primer, 2.5 $\mathrm{mM} \mathrm{MgCl} 2$ and $20 \mu \mathrm{l}$ of the extracted DNA. Cycling protocol was 75 seconds at $95^{\circ} \mathrm{C}$, followed by 60 cycles of denaturation

Abbreviations: PCR, polymerase chain reaction; TETR PCR, touchdown enzyme time release polymerase chain reaction 
Table 1 C pneumoniae in abdominal aorta aneurysms (AAA)

\begin{tabular}{|c|c|c|}
\hline Author & Year of publication & C pneumoniae + case $(\mathrm{s}) /$ total cases \\
\hline Maraha et al' ${ }^{11}$ & 2001 & $\begin{array}{l}18 / 88(20 \%) \text { in AAA } \\
8 / 88(9 \%) \text { in controls }\end{array}$ \\
\hline Karlsson et aP & 2000 & $20 / 26$ \\
\hline Alakarppa et $a l^{12}$ & 1999 & $5 / 12$ \\
\hline Meijer et $a^{l^{13}}$ & 1999 & $\begin{array}{l}0 / 18 \text { (PCR) } \\
15 / 19 \text { (antigen) }\end{array}$ \\
\hline Petersen et $a^{\beta}$ & 1998 & $\begin{array}{l}14 / 40(35 \%) \text { in atherosclerosis } \\
2 / 40(5 \%) \text { in normal cases }\end{array}$ \\
\hline Lindholt et al & 1998 & $\begin{array}{l}10 / 18 \text { (antigen) } \\
0 / 18 \text { (PCR) }\end{array}$ \\
\hline Juvonen et alo & 1997 & $6 / 6$ \\
\hline Blasi et al ${ }^{14}$ & 1996 & $26 / 51$ (PCR) \\
\hline
\end{tabular}

\begin{tabular}{|c|c|c|c|}
\hline Author & $\begin{array}{l}\text { Year of } \\
\text { publication }\end{array}$ & Detection method & C pneumoniae positivity in $\%$ \\
\hline Apfalter et $a l^{15}$ & 2000 & Cell culture & $\begin{array}{l}7.9 \% \\
\text { (in } 38 \text { patients with infrarenal abdominal } \\
\text { aorta aneurysm, carotid artery, femoral } \\
\text { artery, etc) }\end{array}$ \\
\hline Vink et $a^{\text {plo }}$ & 2001 & $\begin{array}{l}\text { C pneumoniae specific } \\
\text { monoclonal antibodies }\end{array}$ & $\begin{array}{l}67 \% \text { in abdominal aorta } \\
41 \% \text { internal and common iliac arteries } \\
33 \% \text { in coronary arteries } \\
2 \% \text { in cerebral arteries } \\
0 \% \text { radial artery } \\
\text { (in } 24 \text { patients with } 33 \text { arterial samples) }\end{array}$ \\
\hline
\end{tabular}

\section{Table 3 Aneurysm cases}

\begin{tabular}{lll}
\hline Age & Sex & Site of the aneurysm \\
\hline 52 & F & R-ACM+AcoA+L-ICA+M2 \\
48 & F & R-Copht. \\
46 & $M$ & R-ACM (giant) \\
61 & $M$ & L-A1 \\
67 & F & R-PcoA \\
36 & $M$ & R-ACM \\
64 & $M$ & L-A2 + BA \\
43 & F & R-PICA \\
46 & $M$ & R-A2 \\
45 & $M$ & R-ACM (giant) \\
23 & $M$ & R-P1-2 \\
68 & $M$ & R-PcoA \\
53 & F & L-PCA \\
39 & $M$ & R-PcoA \\
40 & F & AcoA \\
\hline
\end{tabular}

Table 4 Tumour cases

\begin{tabular}{lll}
\hline Age & Sex & Histopathology \\
\hline 43 & $M$ & Craniopharyngioma \\
28 & $F$ & Fourth ventricule ependymoma \\
\hline
\end{tabular}

at $94^{\circ} \mathrm{C}$ for 45 seconds, annealing beginning at $64^{\circ} \mathrm{C}$ and ending at $52^{\circ} \mathrm{C}$ for 45 seconds, and extension at $72^{\circ} \mathrm{C}$ for one minute. The annealing temperature was lowered $10^{\circ} \mathrm{C}$ every four cycles until $52^{\circ} \mathrm{C}$ and this temperature was kept until the end of the cycling process.

CP1-CP2 primers with nested pair CPC-CPD were used for the ompA nested PCR. The first round of amplification used 1.5
$\mathrm{mM} \mathrm{MgCl} 2,0.4 \mu \mathrm{M}$ of each primer and $20 \mu \mathrm{l}$ of the extracted DNA. Cycling consisted of nine minutes at $95^{\circ} \mathrm{C}$ for Taq polymerase activation, 20 cycles of one minute at $94^{\circ} \mathrm{C}$, one minutes at $65^{\circ} \mathrm{C}$ (temperature was decreased $0.5^{\circ} \mathrm{C}$ for each cycle) and one minute at $72^{\circ} \mathrm{C}$ plus an additional 20 cycles of one minute at $94^{\circ} \mathrm{C}$, one minute at $55^{\circ} \mathrm{C}$ and one minute at $72^{\circ} \mathrm{C}$. The PCR products amplified by the outer primer pair were diluted 1:5 and $5 \mu$ was added to a new PCR mixture containing $1 \mu \mathrm{M}$ of each primer and $3 \mathrm{mM}$ of $\mathrm{MgCl} 2$.

Cycling protocol entailed nine minutes at $95^{\circ} \mathrm{C}$ for $\mathrm{Taq}$ polymerase activation, 30 cycles of one minute at $94^{\circ} \mathrm{C}$, one minute at $50^{\circ} \mathrm{C}$ and one minute at $72^{\circ} \mathrm{C}$.

\section{Detection of the human $\beta$ globin gene}

For extraction and PCR inhibition control, a fragment of the human $\beta$ globin gene was amplified as previously described. ${ }^{19}$

All amplification products were analysed by agarose gel electrophoresis and ethidium bromide staining. The expected amplicon sizes were 197bp for TETR PCR, 333bp for ompA outer primer pair, 207bp for ompA inner primer pair and 536 bp for the human $\beta$ globin gene.

\section{RESULTS}

Two different PCR assays were performed to detect $C$ pneumoniae DNA. Both TETR PCR and ompA nested PCR was sensitive to detect $10^{-3}$ colony forming units. All samples were negative for $C$ pneumoniae DNA (fig 1 and 2). A 536bp fragment of the human $\beta$ globin gene was detected in all of the samples except one (fig 3 ).

\section{DISCUSSION}

The term "mycotic aneurysm" was first used by Osler in $1885 .^{20}$ Subsequently Stengel and Wolferth (1923) reported 217 cases, including their own, of aneurysms developing during bacterial infections. ${ }^{21}$ Among these 42 cases had intracranial aneuryms, and since that time at least 30 cases of mycotic 


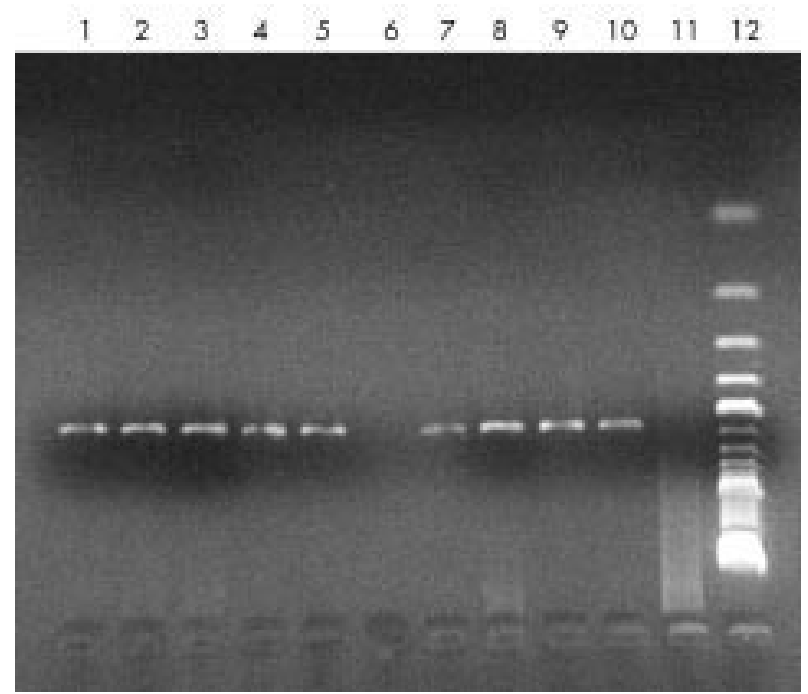

Figure 1 C pneumoniae TETR PCR of clinical samples. Lanes 1 to 3,5 to 7 clinical samples. Lanes 4 and 8 negative control (water). Lanes 9 and 11 positive control (C pneumoniae $4 \times 10^{-1}$ and $4 \times 10^{-2}$ CFU). Lane 10 water. Lane 12 DNA molecular weight marker (XIV; 100 bp ladder, Roche Diagnostics)

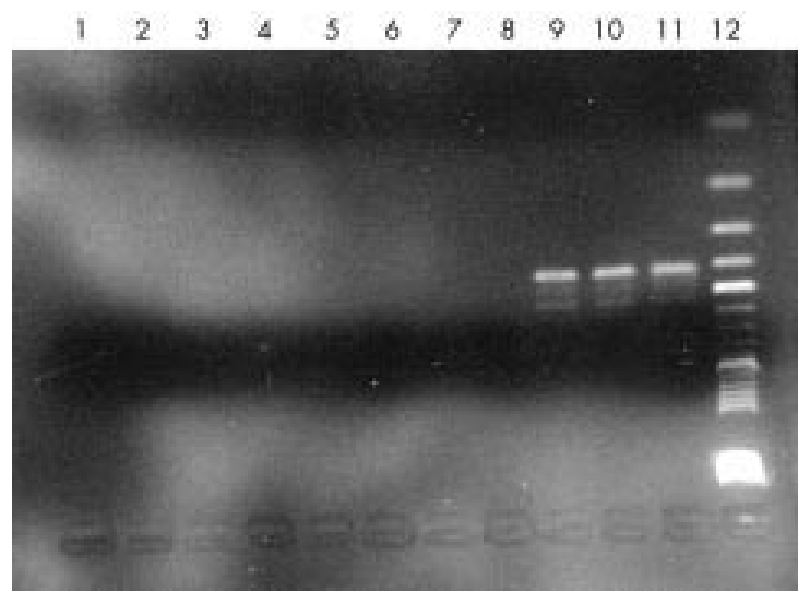

Figure 2 C pneumoniae OmpA PCR of clinical samples. Lanes 1 to 7 clinical samples. Lane 8 negative control (water). Lanes 9 to 11 positive controls ( $C$ pneumoniae 40,4 , and $4 \times 10^{-1} \mathrm{CFU}$ respectively). Lane 12 DNA molecular weight marker (XIII; 50 bp ladder, Roche Diagnostics).

aneurysms have been reported. ${ }^{22}$ A review of 1126 cases of intracranial aneuryms in $1939^{23}$ showed an incidence of $6 \%$ mycotic aneurysms. After the introduction of antibiotic treatment of subacute bacterial endocarditis, bacterial cerebral aneurysms have become quite rare. As Yasargil stated "...A more likely error in present-day diagnosis is the failure to consider an aneurysm to be of bacterial embolic origin...". ${ }^{24}$ Before the antibiotic era, cerebral aneurysms secondary to infected emboli from the vegetations of endocarditis were not uncommon.

At the beginning of the past century, mycotic aneurysms were thought to account for about one quarter of intracranial aneurysms. ${ }^{24} 25$

The term "arteriosclerotic aneurysm" is used to describe fusiform dilatation of a cerebral vessel in which the wall has undergone atheromatous degeneration. The first comprehensive discussion of this entity was by Dandy in 1944, who encountered 11 cases of elongated and tortuos vascular arteries in the course of posterior fossa procedures. ${ }^{26}$ Such serpentine dilatation of the vertebral basilar or internal carotid

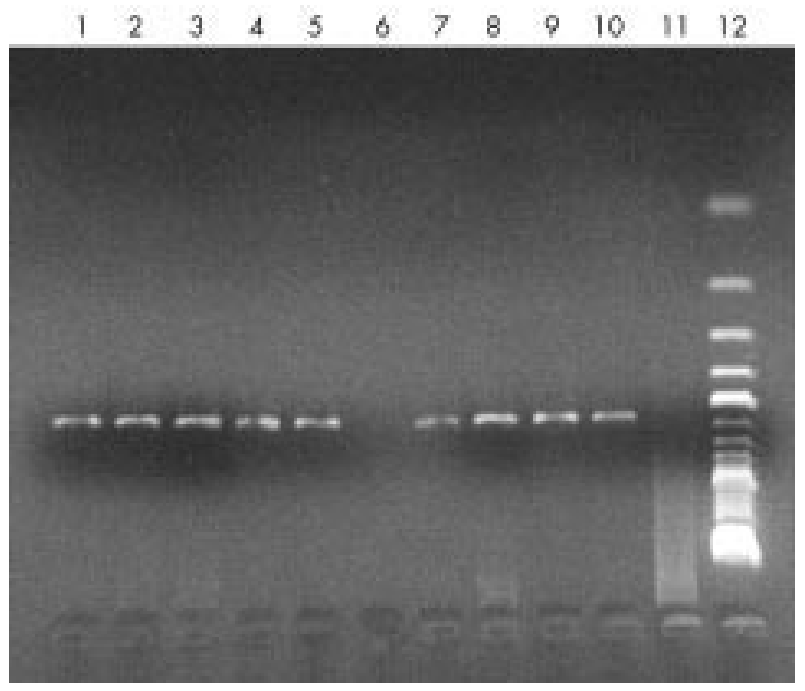

Figure $3 \beta$ globin control PCR. Lane 1 to 5 and 7 to 11 clinical samples. Lane 6 negative control (water). Lane 12 DNA molecular weight marker (XIV; 100 bp ladder, Roche Diagnostics).

arteries is a frequent occurence in patients with severe atherosclerosis. ${ }^{27}$ These lesions are usually classified as atherosclerotic aneurysms, although they are not necessarily associated with senile ectasia or atherosclerosis of the vessel, for example, Marfan syndrome, megalodolichobasilaris or idiopathic mediannecrosis. Atherosclerotic aneurysms accounted for about $50 \%$ of the lesions in older statistics ${ }^{28}$ and are found in $8 \%$ to $16 \%$ of Housepian and Pool (1958) and Jellinger's (1979) series. ${ }^{27}{ }^{29}$ Ohara et al (1979) distinguished two types of arteriosclerotic aneurysms. ${ }^{30}$ One is the type where the trunk arteries, such as the basilar artery, themselves, swell to a fusiform shape (Fusiform aneurysm). The other is the type where a saccular aneurysm arises having no relation to the arterial forks with considerable sclerosis of the parental artery. In Suzuki's series (1979) eleven of 1116 aneurysm cases (1\%) had sclerotic aneurysms. ${ }^{31}$

C pneumoniae has been associated with atherosclerotic cardiovascular disease by both seroepidemiological studies and direct detection of the organism in atherosclerotic plaque by electron microscopy, immunocytochemistry, and PCR. ${ }^{32}$ The role of inflammatory reactions in the pathogenesis of atherosclerosis is widely accepted. Recently, an increasing body of evidence has linked infections to atherosclerosis. It is hypothesised that infections could interact with other risk factors of vascular disease, increasing the endothelial damage and the production of atherosclerotic plaques. Several different infectious agents have been related to the atherosclerosis genesis: mainly herpesvirus, Helicobacter pylori, and C pneumoniae. Several lines of evidence strongly link $C$ pneumoniae to atherosclerosis. Consequently, several studies evaluating the effectiveness of antibiotic treatment in the reduction of cardiac ischaemic events in patients with $C$ pneumoniae seropositivity have been performed.

On the other hand several reports show lack of association between seropositivity to $C$ pneumoniae and carotid atherosclerosis $^{33}$ and even $C$ pneumoniae antibodies and high lipoprotein $\alpha$ levels do not predict ischaemic cerebral infarctions. ${ }^{34}$ In contrast with previous published papers, Nobel et al could not confirm an association of C Pneumoniae infection with an acute coronary event. ${ }^{35}$ Gibbs et al research showed that the presence of the infectious organism has little detectable impact on plaque instability when measured by clinically significant markers. ${ }^{10}$ This raises important questions for the rationale of antibiotic therapy in atherosclerosis. ${ }^{36}$ The validity of the hypothesis that infection contributes to atherosclerosis has not been definitively established, although the evidence is becoming compelling, with 
several interesting studies presented at the 2001 ACC meeting (S E Epstein, 50th annual scientific session of the American College of Cardiology, 19 March 2001). Evidence is also acumulating that autoimmune responses, perhaps triggered by infection, may be one of the mechanisms contributing to atherogenesis. The concepts are intriguing and will undoubtedly serve as the focus of many investigative studies presented at future meetings (50th annual scientific session of the American College of Cardiology). In the study of Vink et al the prevalences of $C$ pneumoniae at multiple locations in the arterial system within the same person were observed as highest in the abdominal aorta $(67 \%)$, internal and common iliac arteries $(41 \%)$, and coronary arteries $(33 \%)$. The lowest prevalences were observed in the radial $(0 \%)$ and cerebral $(2 \%)$ arteries. ${ }^{16} \mathrm{C}$ pneumoniae was mostly observed at locations that are related to clinically relevant features. Within the patient group, the distribution of $C$ pneumoniae is associated with the distribution of atherosclerosis. The role of the micro-organism in atherosclerotic disease remains to be elucidated. This study and our results with cerebral aneurysms show at least the possible role of $C$ pneumoniae in the patogenesis of the cerebral aneurysms.

In this study, negative results of PCR may be discussed (or questioned) for the presence of PCR inhibitors in the samples or the inefficiency of the PCR. For the assesment of these factors; fragment of human $\beta$ globin gene was investigated in every sample as an endogenous control. The sensitivity of the PCR methods was determined with positive controls of $C$ pneumoniae culture samples with a known genomes. All the samples were found to be positive for $\beta$ globin gene indicating the absence of PCR inhibitors. Performed TETR PCR and ompA PCR methods were found to be as sensitive to detect $4 \times 10^{-2}$ genomes per reaction. We cannot exclude the contribution of $C$ pneumoniae in development of intracranial aneurysms despite the result of this study. Further studies on the possible role of $C$ pneumoniae or any other micro-organisms (such as $H$ pylori, citomegalovirus, autoantibodies against "heat shock" proteins, hepatitis A virus, herpes simplex virus 1 and 2 (HSVl-2), Porphyromonas gingivalis, et al) in the pathogenesis of aneurysms should be performed.

\section{Authors' affiliations}

S Cagli, N Oktar, T Dalbasti, N Özdamar, Department of Neurosurgery, Ege University School of Medicine, Izmir, Turkey S Erensoy, S Göksel, A Bilgiç, Department of Clinical Microbiology, Ege University School of Medicine

A Sayiner, Dokuz Eylül University, Izmir, Turkey

Competing interests: none declared.

\section{REFERENCES}

1 Grayston JT, Kuo CC, Campbell LA, et al. Chlamydia pneumoniae and cardiovascular disease. Cardiologia 1997;42:1145-51.

2 Gura T. Infections: A cause of artery-clogging plaques? Science 1998;281:35-7.

3 Ong G, Thomas BJ, Mansfield AO, et al. Detection and widespread distribution of Chlamydia pneumoniae in the vascular system and its possible implications. J Clin Pathol 1996;49:102-6.

4 Hatch T. Chlamydia: old ideas crushed, new mysteries bared. Science 1998;282:638-9.

5 Blanchard JF, Armenian HK, Peeling R, et al. The relation between Chlamydia pneumoniae infection and abdominal aortic aneurysm: case-control study. Clin Infect Dis 2000;30:946-7.

6 Juvonen J, Juvonen T, Laurila A, et al. Demonstration of Chlamydia pneumoniae in the walls of abdominal aortic aneurysms. J Vasc Surg 1997:25:499-505

7 Karlsson L, Gnarpe J, Naas J, et al. Detection of viable Chlamydia pneumoniae in abdominal aortic aneurysms. Eur J Vas Endovas Surg 2000; 19:630-5.
8 Petersen E, Boman J, Persson K, et al. Chlamydia pneumoniae in human abdominal aortic aneurysms. Eur J Vasc Endovasc Surg 1998; 15: 138-42

9 Lindholt JS, Ostergard L, Henneberg EW, et al. Failure to demonstrate Chlamydia Pneumoniae in symptomatic abdominal aortic anuerysms by a nested polymerase chain reaction (PCR). Eur J Endovasc Surg 1998; 15:161-4.

10 Gibbs RGJ, Sian M, Mitchell AWM, et al. Chlamydia pneumoniae does not influence atherosclerotic plaque behavior in patients with established carotid artery stenosis. Stroke 2000;31:2930-5.

11 Maraha B, den Heijer M, Wullink M, et al. Detection of Chlamydia pneumoniae DNA in buffy-coat samples of patients with abdominal aortic aneurysm. Eur J Clin Microbiol Infect Dis 2001;20:111-16.

12 Alakarppa H, Surcel HM, Laitinen K, et al. Detection of Chlamydia pneumoniae by colorimetric in situ hybridization. APMIS 1999; 107:451-4.

13 Meijer A, van Der Vliet JA, Roholl PJ, et al. Chlamydia pneumoniae in abdominal aortic aneurysms: abundance of membrane components in the absence of heat shock protein 60 and DNA. Arterioscler Thromb Vasc Biol 1999; 19:2680-6.

14 Blasi F, Denti F, Erba $M$, et al.Detection of Chlamydia pneumoniae but not Helicobacter pylori in atherosclerotic plaques of aortic aneurysms. $J$ Clin Microbiol 1996:34:2766-9.

15 Apfalter $\mathbf{P}$, Loidl $M$, Nadrchal $R$, et al. Isolation and continuous growth of Chlamydia pneumoniae from arterectomy specimens. Eur J Clin Microbiol Infect Dis 2000;19:305-8

16 Vink A, Poppen M, Schoneveld AH, et al. Distribution of Chlamydia pneumoniae in the human arterial system and its relation to the local amount of atherosclerosis within the individual. Circulation 2001:103:1613-17.

17 Madico G, Quinn TC, Boman J, et al. Touchdown enzyme time release-PCR for detection and identification of Chlamydia trochomatis, $C$ pneumoniae, and C.psittaci using the 16S and 16S-23S spacer rRNA genes. J Clin Microbiol 2000;38:1085-93.

18 Mahony JB. Analytical sensitivity, reproducibility of results and clinical performance of five PCR assays for detecting Chlamydia pneumoniae DNA in peripheral mononuclear cells. J Clin Microbiol 2000;38:2622-7

19 Randall K, Saiki RK. Amplification of genomic DNA. In: Innis MA, Gelfend DH, Sninsky JJ, et al,eds. PCR protocols. A guide to methods and applications. San Diego: Academic Press, 1990:13-19.

20 Osler W. The Gulstonian lectures on malignant endocarditis. BM $1885 ; 1: 467-70$

21 Stengel A, Wolferth CC. Mycotic (bacterial) aneurysms of intravascular origin. Arch Intern Med 1923:31:527-54

22 Iwabuchi T, Kurushima Y, Fukawa O, et al. Multiple mycotic cerebral aneurysms. In: Suzuki J. Cerebral aneurysms. Tokyo: Neuron, 1979:690-6

23 McDonald CA, Korb M. Intracranial aneurysms. Arch Neurol Psychiatry (Chic) 1939:42:298-325

24 Yasargil MG. Microneurosurgery I. Microsurgical anatomy of the basal cisterns and vessels of the brain, diagnostic studies, general operative techniques and pathological considerations of the intracranial anerysms. Stuttgart: Georg Thieme Verlag, 1984:28

25 Ozdamar N, Kumral K, Akyurekli O. Enlargement and thrombosis of the mycotic aneurysms. J Neurol Sci (Turk) 1988:5:255-9.

26 Dandy WE. Intracranial arterial aneurysms. Vol VII. Ithaca, NY: Comstock, 1944:147.

27 Jellinger K. Pathology and aetiology of intracranial aneurysms. In: Pia $\mathrm{HW}$, Langmaid C, Zierski J. Cerebral aneurysms, advances in diagnosis and therapy. Berlin: Springer, 1979:5-19.

28 McCormick WF, Acosta-Rua GJ. The size of intracranial saccular aneurysms. An autopsy study. J Neurosurg 1970;33:422-7.

29 Housepian EM, Pool JL. A systemic analysis of intracranial aneurysm from the autopsy file of the Presbyterian hospital 1914 to 1956.J Neuropathol Exp Neurol 1958;17:409-23.

30 Ohara H, Sakamoto T, Suzuki J. Cerebral aneurysms. In: Suzuki J. Cerebral aneurysms. Tokyo: Neuron, 1979:673-82.

31 Suzuki J. Cerebral aneurysms. Tokyo: Neuron, 1979.

32 Jackson LA, Campbell LA, Kuo CC, et al. Isolation of Chlamydia pneumoniae from a carotid endarterectomy specimen. J Infect Dis 1997:176:292-5.

33 Coles KA, Plant AJ, Riley TV, et al. Lack of association between seropositivity to Chlamydia pneumoniae and carotid atherosclerosis. Am J Cardiol 1999;84:825-8

34 Glader CA, Stegmayr B, Boman J, et al. Chlamydia pneumoniae antibodies and high lipoprotein (a) levels do not predict ischemic cerebral infartions. Results from a nested case-control study in Northern Sweden. Stroke 1999;30:2013-18.

35 Nobel M, De Torrente A, Peter O, et al. No serological evidence of association between chlamydia pneumoniae infection and acute coronary heart disease. Scand J Infect Dis 1999;31:261-4.

36 Mosorin M, Juvonen J, Biancari F, et al. Use of doxycycline to decrease the growth rate of abdominal aortic aneurysms: a randomized, double-blind, placebo-controlled pilot study. J Vasc Surg 2001;34:757-81. 


\section{CORRESPONDENCE}

\section{Neutralising antibodies to interferon $\beta$ during the treatment of multiple sclerosis}

Giovannoni and colleagues are to be commended for their detailed analysis of the impact of neutralising antibodies (NAB) to interferon $\beta$ (IFN $\beta$ ) during the treatment of multiple sclerosis. ${ }^{1}$ We are in general agreement with many of their statements and conclusions, but a few points should be discussed in a wider context.

With respect to the clinical significance of neutralising antibodies to IFN $\beta$, the authors state that "IFN $\beta$ has little if any clinical and MRI efficacy in the presence of neutralising antibodies." We think it is appropriate to be more circumspect, as most published studies suggest that in $\mathrm{NAB}$ positive patients, clinical (and MRI) efficacy of interferon treatment is present when compared to placebo, and that there is some evidence that more immunogenic higher dose treatment can be more effective than less immunogenic lower dose treatment. ${ }^{2}$ Giovannoni et al appear to base their statement on the increase in T2 burden of disease in the NAB positive group in the PRISMS extension study, but they do no mention similar comparisons which, if interpreted in the same way, would indicate that the NAB positive group does better than the placebo group. ${ }^{3}$ For example, the relapse rate in placebo patients was 1.3 year in years one to two, whereas it was 0.81 and 0.50 in NAB positive and $\mathrm{NAB}$ negative high dose patients in years three to four. We recognise that this specific comparison is fraught with difficulties owing to time trends in the relapse data, but these potential difficulties are present in all such comparisons. In a recent paper we report-in probably the largest study of neutralising antibodies in multiple sclerosis, describing $100 \mathrm{NAB}$ positive patients in the European SPMS study-that high titres of neutralising antibodies do have a clinical impact, but that this impact is rather limited, and that on both clinical and MRI measures patients on active treatment who develop neutralising antibodies continue to do consistently better than those on placebo. ${ }^{4}$ The main conclusions of this paper are based on longitudinal analyses of the data on those patients who switched from NAB negative to $\mathrm{NAB}$ positive status; this is the only statistical approach that allows a direct assessment of whether the change from $\mathrm{NAB}$ negative to $\mathrm{NAB}$ positive status is associated with diminished efficacy of a treatment. Cross sectional comparisons are not fully reliable for establishing the impact of neutralising antibody positivity, as NAB positive and negative subgroups may differ on baseline variables (maybe unobserved) that are predictive of both neutralising antibody formation and diminished clinical response.

Giovannoni et al also state that during continued treatment "in the case of IFN $\beta-\mathrm{Ib}$ some $\mathrm{NAB}$ positive patients revert to $\mathrm{NAB}$ negative status over two to five years of follow up" and that "patients with high titres of neutralising antibodies seldom revert to being negative." In the European study of IFN $\beta$ - $1 \mathrm{~b}$ in secondary progressive multiple sclerosis the proportion of treated patients who have been $\mathrm{NAB}$ positive and subsequently revert back to being $\mathrm{NAB}$ negative is about $40 \%$ after a treatment duration up to three years (without convincing evidence that patients with higher titres revert less frequently), whereas in the study by Rice et al this percentage is close to $80 \%$ after a mean treatment duration of more than eight years. ${ }^{4}$

In our opinion, these data suggest that the clinical impact of neutralising antibodies to IFN $\beta$ during the treatment of multiple sclerosis may be more limited and more transient than suggested in the editorial, and that the development of neutralising antibodies in itself does not provide justification for switching treatments or for considering (aggressive) strategies to reduce or revert the development of neutralising antibodies. Given the current rather uncertain state of knowledge concerning the impact of neutralising antibodies, we advocate that treatment decisions should be based on clinical grounds rather than on neutralising antibody titres.

C H Polman

Department of Neurology, VU Medical Centre, 1007 MB Amsterdam, Netherlands

L Kappos

Department of Neurology, University Hospitals Basel, Switzerland

J Petkau

Department of Statistics, University of British Columbia, Vancouver, Canada

A Thompson

Institute of Neurology, University College London,

Correspondence to: Professor C H Polman ch.polman@vumc.n

\section{References}

Giovannoni G, Munschaver FE, Deisenhammer $F$. Neutralising antibodies to interferon $\beta$ during treatment of multiple sclerosis. J Neurol Neurosurg Psychiatry 2002;73:465-9.

2 Durelli L, Verdun E, Barbero $\mathrm{P}$, et al. Every-other-day interferon beta- $1 \mathrm{~b}$ versus once-weekly interferon beta- $1^{\circ}$ for multiple sclerosis: results of a 2-year prospective randomised multicentre study (INCOMIN) lancet 2002;359:1453-60.

3 PRISMS-4. Long-term efficacy of interferon beta-la in relapsing MS. Neurology 2001;56:1628-36

4 Polman C, Kappos L, White R, et al. Neutralizing antibodies during treatment of secondary progressive MS with interferon beta-1b. Neurology 2003;60:37-43.

5 Rice GP, Paszner B, Oger J, et al. The evolution of neutralizing antibodies in multiple sclerosis patients treated with interferon beta-1 b. Neurology 1999;52:1277-9.

\section{Neutralising antibodies to interferon $\beta$}

I read the editorial by Dr G Giovannoni and colleagues ${ }^{1}$ with great interest. I have, however, to report a minor error concerning the list of the excipients of the Rebif reported in their table 1. In the table the authors reported the following excipients: mannitol, HSA, sodium acetate, acetic acid, sodium chloride. Actually, as you can check in the summary of product characteristics published from EMEA (www.emea.eu.int) on 29 March 1999, in the list of excipients sodium chloride is absent, whereas sodium hydroxide is present.

C Ortenzi

Department of Molecular, Cellular and Animal Biology, University of Camerino, 62032 Camerino, Italy; claudio.ortenzi@tin.it

\section{Reference}

1 Giovannoni G, Munschaver FE, Deisenhammer F. Neutralising antibodies to interferon $\beta$ during treatment of multiple sclerosis. J Neurol Neurosurg Psychiatry 2002:73:465-9.

\section{Authors' reply}

We would like to thank Dr Ortenzi for pointing out our transcription error in relation to the excipients of Rebif ${ }^{\circledR}$ in table 1 of our

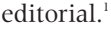

We agree with Polman and colleagues that recent comparisons show that the more immunogenic higher dose interferon $\beta$ (IFN $\beta$ ) preparations are more efficacious than the lower dose less immunogenic preparations over 24 month $^{2}$ and six month ${ }^{3}$ periods of observation. However, as discussed in our editorial, the development of neutralising antibodies and their effects on the clinical efficacy of IFN $\beta$ are delayed. In the PRISMS study the effect of neutralising antibodies on clinical efficacy only became apparent in years 3-4. In the pivotal IFN $\beta$-lb study an effect on relapse rate was only observed in the 19-24 and 25-30 month epochs. ${ }^{5}$ Hence we would argue that these comparative studies ${ }^{2}{ }^{3}$ are simply too short, and in the case of the INCOMIN trial underpowered $(\mathrm{n}=188),{ }^{2}$ to demonstrate an effect of neutralising antibodies on clinical efficacy. It is therefore impossible to extrapolate the significant short term differences shown in these studies beyond the periods of observation reported.

Because of regression to mean and the well documented tendency for the relapse rate to decrease with disease duration, it is not possible to draw any meaningful conclusions from a comparison of the relapse rate in years $1-2$ and years 3-4 from the PRISMS extension study ${ }^{46}$ In addition to the impact of neutralising antibodies on relapse rate, the PRISMS extension study clearly shows-using the more objective T2 lesion volume or burden of disease-that the average annualised increase in lesion volume over four years in the neutralising antibody positive $(\mathrm{NAB}+)$ patients is similar to the increase in the annualised lesion volume in the placebo treated patients in the first two years of the study $(\mathrm{NAB}+4.4 \% v$ placebo $5.45 \%) .{ }^{46}$ Similarly, in the IFN $\beta$-lb study, ${ }^{5}$ the annualised relapse rate of $\mathrm{NAB}+$ patients is identical to patients on placebo $(1.08 v 1.06)$. In the IFN $\beta-1 a$ (Avonex ${ }^{\circledR}$ ) trial, ${ }^{7}$ the impact of neutralising antibodies was limited to MRI outcomes. The failure of neutralising antibodies to have an effect on disease progression and relapse rate in this study probably reflects the size and duration of follow $\mathrm{u}$, as the study was terminated prematurely. It is these data from the pivotal relapsing multiple sclerosis clinical 
trials, and other studies on in vivo markers of IFN $\beta$ activity discussed in our editorial, that we use to support our statement that "interferon $\beta$ has little if any clinical and MRI efficacy in the presence of neutralising antibodies."

Data on the impact of neutralising antibodies in secondary progressive multiple sclerosis (SPMS) trials is less clear. This is to be expected, however, as the efficacy of IFN $\beta$ on disease progression-the primary outcome measure in SPMS trials-is limited and hence it would be difficult to demonstrate a significant impact on neutralising antibodies on the primary outcome measure when the actual therapeutic intervention itself is only marginally effective. ${ }^{89}$ It would be very surprising if neutralising antibodies had a significant impact on disease progression, as none of the trials is powered to detect an effect of neutralising antibodies on this outcome. For example, in the European SPMS study, 100/360 $(28 \%)$ of IFN $\beta-1 b$ treated patients became $\mathrm{NAB}+$ (titre $>20$ ) over the course of the trial. $^{10}$ Taking a conservative approach by applying the results from the trial, ${ }^{810}$ and assuming that $\mathrm{NAB}+$ patients behave as if they are on placebo and $\mathrm{NAB}$ - patients behave like the original IFN $\beta$-lb treated cohort, one would expect $49.8 \%$ of the $100 \mathrm{NAB}+$ patients to progress over three years, compared with $38.9 \%$ of the $260 \mathrm{NAB}-$ patients. At the same level of significance (0.029) from the original study, a two sided test would only have a 35\% chance of detecting a significant difference between $\mathrm{NAB}+$ and $\mathrm{NAB}-$ patients (Fisher's exact test). Compare this to a power of $80 \%$ used in the design of the original study. This power calculation is an overestimate as it ignores the therapeutic effect observed before the development of neutralising antibodies, as evidenced in this study, ${ }^{10}$ which if taken into account has the potential to further reduce the power of the subanalysis. Polman and colleagues further reduce the power of the subanalysis by limiting the longitudinal study to "switchers" - that is, clinical responses are compared within individual patients during $\mathrm{NAB}-$ and $\mathrm{NAB}+$ periods. $^{10}$ This longitudinal approach reduces the number of patients available for analysis and potentially shortens the period of observation. A longitudinal approach would seem reasonable if there are no carryover therapeutic effects of IFN $\beta$-lb treatment from the $\mathrm{NAB}-$ to $\mathrm{NAB}+$ phase and if the follow up in the $\mathrm{NAB}+$ phase is of suffi cient duration to account for the delayed effects (24 to 48 months) of neutralising antibodies on clinical efficacy. In this study the mean follow up in the $\mathrm{NAB}+$ phase would be on average too short (less than 24 months) for one to be confident of excluding a delayed effect of neutralising antibodies on disease progression. Despite the lack of power of these subanalyses, they produce some surprising results. In the cross sectional study there was a trend towards greater disease activity in the $\mathrm{NAB}+$ group in the third year, and a significant percentage $\mathrm{T} 2$ volume change from baseline to year 1 , year 2 , and the last visit ${ }^{10}$; in the underpowered and potentially flawed longitudinal analysis there was no indication of an attenuation of treatment effects on disability progression but, surprisingly considering the lower relapse rate in secondary progressive multiple sclerosis, there was a robust effect on relapse rate. ${ }^{10}$

Another way of interpreting the European SPMS NAB data as presented by Polman and colleagues is that the much higher dose of IFN $\beta$-lb ( $875 \mu \mathrm{g} /$ week) given in that study, in comparison with the lower licensed doses of
IFN $\beta$-la (30-132 $\mu \mathrm{g} /$ week), acted to quench some of the neutralising activity of the antibodies. ${ }^{10}$ Similarly, the higher doses may be responsible for inducing high dose tolerance in a subset of the patients. These phenomena are well observed with other biologicals in which the read-outs are more objective than in multiple sclerosis-for example, coagulation in anti-factor VIII and glucose levels in anti-insulin antibody positive patients.

Polman and colleagues have misinterpreted our recommendations.' We do not recommend routine screening of neutralising antibodies at present, nor the switching of treatments in $\mathrm{NAB}+$ patients unless clinically justified, nor aggressive strategies to reduce or reverse the development of neutralising antibodies. ${ }^{1}$ We simply state that further research is necessary to assess whether these strategies are appropriate. Polman and colleagues' concluding statement that treatment decisions should be based on clinical grounds rather than on neutralising antibody titres is entirely in keeping with our recommendations.

We disagree with Polman and colleagues' statement that "the clinical impact of neutralising antibodies to interferon $\beta$ during treatment of multiple sclerosis may be more limited and more transient than suggested in the editorial." Short to intermediate term data $(<4$ years $)$ from the relapsing multiple sclerosis studies discussed above ${ }^{47}$ do not support this claim, and long term clinical data (>4 years) on the effects of transient neutralising antibodies on the therapeutic efficacy of IFN $\beta$ - lb do not exist to support the latter half of their claim. In addition, evidence is yet to surface on whether or not the phenomenon of transient high titre neutralising antibodies occurs to a similar degree in patients treated with IFN $\beta$-la; therefore the latter half of their statement, if true, may not be applicable to patients treated with IFN $\beta$ la.

In conclusion, clinicians cannot ignore the issue of neutralising antibodies, particularly in view of the evidence from other fields of medicine in which neutralising antibodies reduce or inhibit the efficacy of a wide range of biologicals, including type I interferons. Why should interferon treatment in multiple sclerosis be any different?

G Giovannoni

Department of Neuroinflammation, Institute of Neurology, Queen Square, London WC1 3BG, UK

F Deisenhammer

Department of Neurology, University of Innsbruck, Innsbruck, Austria

F E Munschauer

William C Baird Multiple Sclerosis Research Center, State University of New York, Buffalo, USA

Correspondence to: Dr Gavin Giovannoni; g.giovannoni@ion.ucl.ac.uk

\section{References}

1 Giovannoni G, Munschauer FE, Deisenhammer F. Neutralising antibodies to interferon beta during the treatment of multiple sclerosis. J Neurol Neurosurg Psychiatry 2002;73:465-9.

2 Durelli L, Verdun E, Barbero $P$, et al. Every-other-day interferon beta- $1 \mathrm{~b}$ versus once-weekly interferon beta-la for multiple sclerosis: results of a 2-year prospective randomised multicentre study (INCOMIN). Lancet 2002;359: 1453-60.

3 Panitch H, Goodin DS, Francis G, et al. Randomized, comparative study of interferon beta-la treatment regimens in MS: the
EVIDENCE trial. Neurology

2002;59:1496-506

4 PRISMS-4. Long-term efficacy of

interferon-beta-la in relapsing MS. Neurology

2001;56:1628-36.

5 Study Groups. Neutralizing antibodies during treatment of multiple sclerosis with interferon beta-1 b: experience during the first three years. The IFNB Multiple Sclerosis Study Group and the University of British Columbia MS/MRI Analysis Group. Neurology 1996:47:889-94.

6 Study Group. Randomised double-blind placebo-controlled study of interferon beta-la in relapsing/remitting multiple sclerosis. PRISMS (prevention of relapses and disability by interferon beta-1 a subcutaneously in multiple sclerosis) Study Group. Lancet 1998;352:1498-504.

7 Jacobs LD, Cookfair DL, Rudick RA, et al. Intramuscular interferon beta-la for disease progression in relapsing multiple sclerosis. The Multiple Sclerosis Collaborative Research Group (MSCRG). Ann Neurol 1996;39:285-94.

8 European Study Group. Placebo-controlled multicentre randomised trial of interferon beta- $1 \mathrm{~b}$ in treatment of secondary progressive multiple sclerosis. European Study Group on interferon beta- $1 \mathrm{~b}$ in secondary progressive MS. Lancet 1998;352:1491-7.

9 SPECTRIMS. Secondary progressive efficacy clinical trial of recombinant interferon-beta-la in MS (SPECTRIMS) study group. Randomized controlled trial of interferon-beta-la in secondary progressive MS: clinical results. Neurology 2001;56: 1496-504.

10 Polman C, Kappos L, White R, et al. Neutralizing antibodies during treatment of secondary progressive MS with interferon $\beta-1 b$. Neurology 2003;60:37-43.

\section{A 1908 systematic review of the laterality of hysterical hemiplegia}

Since the publication of our systematic review of the laterality of functional or medically unexplained weakness and sensory disturbance (1965-2000) we have come across a study from 1908 with a similar aim.

Ernest Jones, later an eminent figure in the psychoanalytic movement, published his paper in French while working as an assistant physician at the London School of Medicine. ${ }^{2}$ He reported on the cumulative analysis of 277 cases of hysterical hemiplegia described by 146 authors in 164 articles published between 1880 and 1908. Most of this material is in French and German and includes cases mentioned in doctoral theses and books.

There was no excess of left sided hemiplegia compared with right in hysteria in his analysis- $54 \%$ had paralysis on the right side and $46 \%$ on the left. This was contrary to the prevailing opinion of the time ${ }^{34}$ and also disagrees with another less systematic review of older studies (covering 100 subjects, 13 publications and 6 authors between 1885-1937).

Jones' conclusions - that the laterality of hysterical hemiplegia has no diagnostic value-were the same as ours. His study has not been cited for at least 40 years (and probably much longer even than that). It has been neglected, like many other negative studies before and since, but it deserves recognition on this subject.

J Stone, C Warlow

Division of Clinical Neurosciences, School of Molecular and Clinical Medicine, Western General Hospital, Crewe Road, Edinburgh EH4 2XU, UK 
A Carson, M Sharpe

Division of Psychiatry, School of Molecular and Clinical Medicine, University of Edinburgh, Royal Edinburgh Hospital, Morningside Park, Edinburgh EHIO 5HF, UK

Correspondence to Dr Stone istone@skull.dcn.ed.ac.uk

\section{References}

1 Stone J, Sharpe M, Carson A, et al. Are functional motor and sensory symptoms really more frequent on the left? A systematic review. I Neurol Neurosurg Psychiatry 2002;73:578-81.

2 Jones $\mathrm{E}$. Le côté affecté par l'hémiplégie hystérique. Rev Neurol 1908;16:193-6.

3 Gowers WR. Hysteria. In: A Manual of diseases of the Nervous System. London: Churchill 1892: 903-60.

4 Briquet $\mathbf{P}$. Traité clinique et thérapeutique de I'Hysterie. Paris: J.B.Ballière, 1859

5 Ley RG. An archival examination of an asymmetry of hysterical conversion symptons. J Clin Neuropsychol 1980;2.

\section{Resolution of psychiatric symptoms secondary to herpes simplex encephalitis}

We read with interest the editorial by Kennedy et al, ${ }^{1}$ detailing the short-term treatment of herpes simplex encephalitis (HSE). We agree with the authors that we canno overemphasise the seriousness of the neuropsychiatric symptoms that a number of these patients display in the long term.

We report a 55 year old woman who was diagnosed with HSE; diagnosis was confirmed with a positive PCR test for herpes simplex in the CSF and acyclovir was started the following day after presentation. After a few weeks the patient's recovery was almost complete and she was discharged home. Six months later, there was an abrupt change when the patient developed insomnia and would sit up all night watching children's videos; she also became hostile and confused She was admitted to a psychiatric unit where she continued to be confused and agitated with episodes of extreme behaviour such as undressing or trying to attack staff.

MRI showed appearances consistent with severe encephalomalacia of the right tempora lobe with evidence of gliosis in the frontal and temporal lobes consistent with previous HSE. It was surprising that the EEG tracing was normal with no focal or epileptiform features.

The patient remained in the psychiatric unit for seven months during which time she failed to respond to different antipsychotic medications and she was heavily sedated. The nursing staff reported that the patient was generally confused but there were distinctive episodes where the patient would stare and then display abusive and disruptive behaviour for periods of up to an hour once or twice a day. Carbamezepine was started and when the patient reached a dose of $400 \mathrm{mg}$ twice daily these episodes ceased completely and the patient's behaviour showed dramatic improvement. She continued to have mild cognitive impairment affecting mainly shortterm memory.

Psychiatric problems after HSE are not uncommon; Hokkanen et al found that psychiatric problems are the main cause of long term disability in these patients. ${ }^{2}$ Despite the fact that clinical relapse of HSE is well documented, ${ }^{3}$ cognitive and psychiatric problems are usually already in place in the acute stage and further deterioration or relapse is uncommon. ${ }^{2}$ In our case the comparatively long period between recovery and onset of behavioural and psychiatric symptoms seemed to cast doubt about the association with the HSE and uncertainty regarding the appropriate treatment

Vallini et al reported successful treatment of a HSE patient presenting with severe emotional liability and explosive emotional outbursts. ${ }^{4}$ The patient responded to carbamezepine, which was started after his EEG showed seizure activity detected in temporal structures. Despite the absence of any EEG abnormalities in our case, it showed a similar favourable response to carbamezepine. We feel that any patient with intermittent behavioural or psychiatric symptoms after HSE should have a therapeutic trial of carbamazepine, even in the absence of any clinical or neurophysiological evidence of seizure activity.

T A-Z K Gaber, M Eshiett

Intermediate Rehabilitation Unit, Leigh Infirmary, Greater Manchester, UK

Correspondence to: Dr T Gaber; t_gaber@mailcity.com

\section{References}

1 Kennedy PGE, Chaudhuri A. Herpes simplex encephalitis. J Neurol Neurosurg Psychiatry 2002;73:237-8.

2 Hokanen L, Launes J. Cognitive recovery instead of decline after acute encephalitis: a prospective follow up study. J Neurol Neurosurg Psychiatry 1997:63:222-7.

3 Dennett C, Klapper PE, Cleator GM. Polymerase chain reaction in the investigation of 'relapse' following herpes simplex encephalitis. J Med Virol 1996;48:129-32.

4 Vallini AD, Burns RL. Carbamezepine as therapy for psychiatric sequel of herpes simplex encephalitis. South Med J 1987;80:1590-2.

\section{Authors' reply}

Gaber and Eshiett report an interesting case of carbamazepine responsive neuropsychiatric syndrome after herpes simplex encephalitis (HSE). Neuropsychiatric symptoms after HSE are well recognised. ${ }^{1}$ The frontotemporal and limbic lesions in HSE are particularly likely to cause behavioural and psychiatric symptoms. Retrospective studies have previously implicated HSE in the delayed syndromes of violen psychoses $^{2}$ and major depression. ${ }^{3}$ However psychiatric disorders are also common after non-herpes virus encephalitis. Hunter and others had emphasised the importance of considering encephalitic antecedents, even if clinically unapparent, in the differential diagnosis of psychiatric patients. ${ }^{4}$ Long term follow up data from the National Childhood Encephalopathy study have shown more recently that $20 \%$ of the affected children developed epilepsy and a similar proportion had behavioural problems, hyperactivity or unsociable behaviour.

Besides being a first line antiepileptic, carbamazepine is also recognised to possess considerable therapeutic value in certain psychoses and is an effective long term treatment for bipolar disorder in some cases. ${ }^{6}$ Carbamazepine responsiveness in this particular case may not, therefore, imply that the psychiatric symptoms were epileptic in origin. However, EEG signatures of epilepsy are often absent interictally, and the presence of psychoses is known to normalise EEG changes ("forced normalisation") in epilepsy patients. ${ }^{7}$ In this particular case, we certainly concur with the authors' use of carbamazepine and were delighted to learn of the favourable response.
P G E Kennedy, A Chaudhuri

Division of Clinical Neurosciences, University Department of Neurology, Ground Floor, Neurology Block, Institute of Neurological Sciences, Southern General Hospital, Glasgow G5 1 4TF, UK

Correspondence to: Professor P G E Kennedy; P.G.Kennedy@clinmed.gla.ac.uk

\section{References}

1 Kennedy PGE, Chaudhuri A. Herpres simplex encephalitis. J Neurol Neurosurg Psychiatry 2002;73:237-8.

2 Cleobury JF, Skinner GRB, Thouless ME, et al. Association between psychopathic disorder and serum antibody to herpes simplex virus (type 1). BM 1971;1:438-9.

3 Lycke E, Norry R, Roos B. A serological study on mentally ill patients with particular reference to the prevalence of herpes virus infections. Br J Psychiatry 1974;124:273-9.

4 Hunter $\mathbf{R}$, Jones M, Malleson A. Abnormal cerebrospinal fluid total protein and gamma globulin levels in 256 patients admitted to a psychiatric unit. J Neurol Sci 1969;9:1 1-38.

5 Madge N, Diamond J, Miller D, et al. The National Childhood Encephalopathy study: a 10 year follow up. A report on the medical, social, behavioural and emotional outcomes after serious, acute, neurological illness in early childhood. Dev Med Child Neurol 1993;35 (suppl 68):1-117.

6 Muller-Oerlinghausen B, Berghofer A Baver M. Bipolar disorder. Lancet 2002;359 241-7.

7 Landolt H. Serial electroencephalographic investigations during psychotic episodes in epileptic patients and during schizophrenic attacks. In: Lorentz de Haas AM, ed. Lectures on epilepsy. Amsterdam: Elsevier,

1958:91-133.

\section{Radiofrequency neurotomy}

In reading the study by Govind and colleagues, ${ }^{1}$ in which they report the findings of an unblinded, uncontrolled, nonrandomised trial of radiofrequency neurotomy for the treatment of third occipital headache, we are surprised that the authors advocate this therapy.

The last statement of the abstract is: "No other form of treatment has been validated for this common form of headache". This implies that Govind et al believe they have validated radiofrequency neurotomy as a form of treatment of third occipital headache. Presumably they are prepared, given the apparently impressive numbers of responders, to forego the usual practice of placebo controlled trial.

We do not understand how the authors can expect this treatment to be realistically adopted in clinical practice with no attempt to validate it the way treatments are meant to be validated, through randomised, placebo controlled trials. The statement in their final paragraph that "some practitioners may be averse to implementing a treatment that requires repetition" could perhaps more appropriately state that "some practitioners may be averse to implementing a treatment that remains unvalidated".

The authors state that one reason they did not do a placebo controlled study is that a previous study has already validated this technique in other patients. ${ }^{2}$ That a single trial of radiofrequency neurotomy in 24 so-called "whiplash patients" is sufficient basis for the current authors to abandon validation with traditional methods seems absurd, especially when closer inspection of that trial lays it in a less positive light. ${ }^{3}$ We do not accept an argument that it was impossible to blind these subjects. It would be entirely reasonable to see just how often a placebo procedure does indeed 
"fool" the patient. Govind et al seem to have already decided that this is not possible, a convenient assumption.

Further, we are concerned that Govind et al state categorically that "among patients with whiplash injuries, third occipital headache is common". The study group from which they determine this prevalence has been reviewed elsewhere, and is wholly inappropriate for a prevalence estimate, being best described as an unusual, highly select, and heterogeneous group of subjects. ${ }^{3}$

It is of note that, in regard to validated therapies for whiplash patients, the current study would have been rejected by the criteria of the Quebec Task Force on Whiplash Associated Disorders. ${ }^{4}$ We suggest that an invasive procedure should not be advocated until it has been subjected to proper study. Fortunately, we are aware that others are undertaking properly controlled trial of this form of therapy.

O Kwan, J Friel

Correspondence to: $\mathrm{Dr} O \mathrm{Kwan}, 207,10708-97$ Street, Edmonton, Alberta, Canada T5H $2 \mathrm{~L} 8$ oliverkwan@shaw.ca

\section{References}

1 Govind J, King W, Bailey B, et al. Radiofrequency neurotomy for the treatment of third occipital headache. J Neurol Neurosurg Psychiatry 2003:74:88-93

2 Lord SM, Barnsley L, Wallis BJ, et al. Percutaneous radio-frequency neurotomy for chronic cervical zygapophysial-joint pain. N Engl J Med 1996;335:1721-6.

3 Kwan O. Friel J. Critical appraisal of facet joints injections for chronic whiplash. Med Sci Monit 2002; 8:RA191-5.

4 Spitzer WO, Skovron ML, Salmi LR, et al. Scientific Monograph of the Quebec Task Force on Whiplash Associated Disorders: redefining "whiplash" and its management Spine 1995;20(suppl 8): 1S-73S.

\section{Authors' reply}

Our study reported an audit of outcomes for a treatment of a condition for which there is no other treatment available. It showed what proportion of patients obtained complete relief of pain, and for how long. Readers who wish to adopt this treatment for their patients can do so. If not, they should explain to their patients that they, personally, cannot offer them any treatment that is known to work; but they should not claim that there is no treatment. Our study shows that there is an option.

A placebo controlled trial would not prove that this treatment does not work. The outcomes should be the same as the benchmark established by our study, unless the operators perform the procedure poorly. A placebo controlled study could only show that all or part of the outcome is attributable to non-specific effects.

We consider this to be an unlikely outcome for we have never encountered in any of our own studies, nor in the literature, results showing that $86 \%$ of patients obtain complete relief of spinal pain following a sham procedure. Radiofrequency neurotomy has been shown to be associated with placebo responses in only a small proportion of patients, and for a limited duration. ${ }^{1}$ They claim that responses to third occipital neurotomy is only a conjecture. In principle it is worthy of testing, but in practice it cannot be tested.
The precepts of informed consent require that participants in a randomised controlled be informed of all the consequences and potential complications of a procedure. Numbness in the territory of the third occipital is an unavoidable side effect of third occipital neurotomy. It is a sign that the target nerve has been coagulated. It is an essential requirement for the procedure to work. The numbness lasts as long as the pain relief lasts. In a double blind trial this side effect cannot be masked. Therefore, patients who underwent a sham procedure would automatically know that they did not have the real treatment. Thereby the patients would be unblinded. Any placebo controlled trial which suffered unblinding would be fatally flawed and, therefore, unacceptable.

Any study that used a control short of a sham procedure would also be flawed, and would not escape criticism. Pundits would argue that patients would recognise that simply blocking the nerve, or simply inserting the electrode without mimicking the two hour procedure assiduously, is an obvious sham, and that any patient so treated would exhibit a nocebo effect.

For these reasons we did not venture to conduct a placebo controlled trial. If Dr Kwan and Dr Friel can show that a sham procedure on the third occipital nerve succeeds in achieving complete relief of pain in $86 \%$ of their patients we will gladly convert to their sham procedure.

We recognise it as a pity that our study would not be accepted by systematic reviews; but that is a problem for those who rely on reviews as the only source of evidence. In that regard we stand in good company. Were we to rely only on systematic reviews, radiofrequency neurotomy for trigeminal neuralgia would not be an accepted treatment; nor would we be allowed to perform appendicectomies.

While others are satisfied to deny care to patients while they engage in purist debates about levels of evidence, we are rewarded with patients grateful for the relief that they obtain, and who report: "you must repeat the procedure because I am never going back to suffering headaches again". If someone devises a better treatment for third occipital headache, we will adopt it. In the meantime

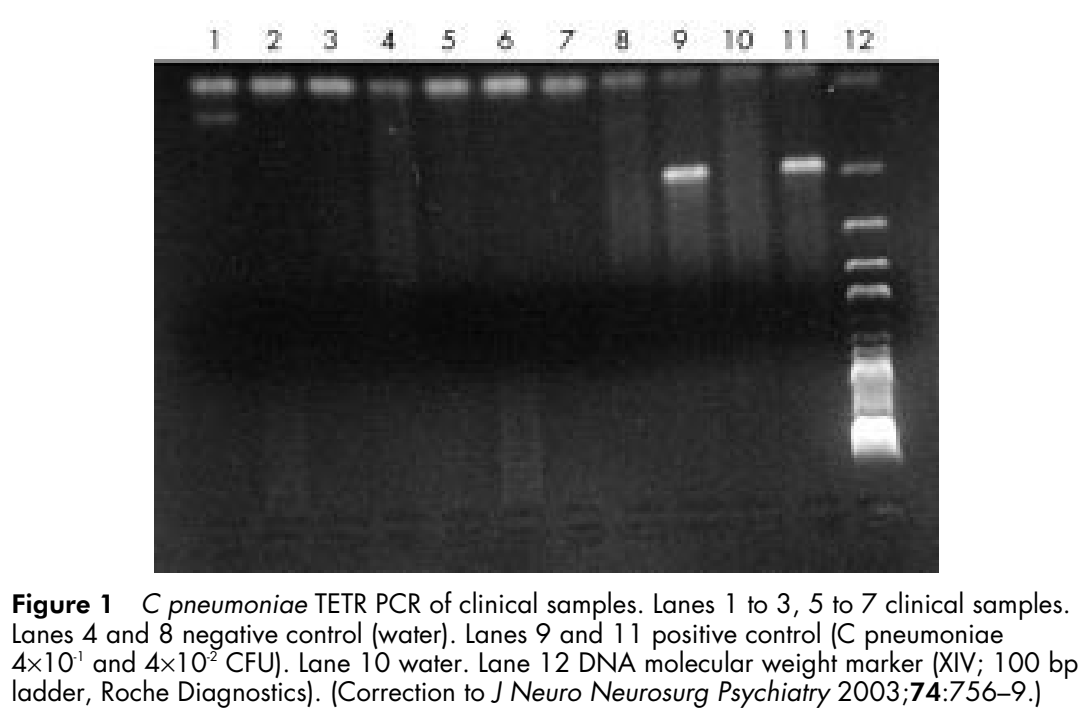

Figure 1 C pneumoniae TETR PCR of clinical samples. Lanes 1 to 3,5 to 7 clinical samples. Lanes 4 and 8 negative control (water). Lanes 9 and 11 positive control (C pneumoniae $4 \times 10^{-1}$ and $\left.4 \times 10^{-2} \mathrm{CFU}\right)$. Lane 10 water. Lane 12 DNA molecular weight marker (XIV; $100 \mathrm{bp}$ ladder, Roche Diagnostics). (Correction to J Neuro Neurosurg Psychiatry 2003;74:756-9.) patients there is nothing we can do for you.

N Bogduk, J Govind, W King

Royal Newcastle Hospital, Australia

Correspondence to: Professor N Bogduk, Department of Clinical Research, Royal Newcastle Hospital, Newcastle, NSW 2300, Australia

\section{Reference}

1 Lord SM, Barnsley L, Wallis BM, et al. Percutaneous radio-frequency neurotomy for chronic cervical zygapophysial joint pain. $N$ Engl J Med 1998;335:1721-6.

\section{CORRECTIONS}

In the neurological picture of the June issue (Komotar JR, Clatterbuck RE. Coccidiomycosis of the brain, mimicking en plaque meningioma. $J$ Neurol Neurosurg Psychiatry 2003;74:806) the initials of the first author were reversed; his name should read as Komotar RJ.

The ordering of the authors in the letter by Soragna D, Tupler R, Ratti et al in the June issue (An Italian family affected by NasuHakola disease with a novel genetic mutation in the TREM2 gene. J Neurol Neurosurg Psychiatry 2003;74:825-6) is incorrect, it should be as follows: D Soragna, L Papi, MT Ratti, R Sestini, R Tupler, L Montalbetti.

The ordering of the authors in the letter by De Tiège, Laureys, Goldman, et al in the July issue (Regional cerebral glucose metabolism in akinetic catatonia and after remission. $J$ Neurol Neurosurg Psychiatry 2003;74:1003-4) is incorrect, it should read as follows: X De Tiège, JC Bier, I Massat, S Laureys, F Lotstra, J Berré, J Mendlewicz, S Goldman.

In the June issue of JNNP fig 1 of the paper by Cagli S, Oktar N, Dalbasti T, et al (Failure to detect Chlamydia pneumoniae DNA in cerebral aneurysmal sac tissue with two different polymerase chain reaction methods. J Neurol Neurosurg Psychiatry 2003;74:756-9) was incorrect. The following figure is the correct image that should have been published. we feel it would be dishonest of us to tell our 